\title{
QUALIDADE EXTERNA E INTERNA DE OVOS OBTIDOS EM DOIS SISTEMAS DE CRIAÇÃO DE GALINHAS POEDEIRAS
}

Luiz Antonio Tizoํㄹ Evandro José Rigo², Cláudio Henrique Gonçalves Barbosa ${ }^{3}$

1. Zootecnista - FAZU - Faculdades Associadas de Uberaba - Uberaba, MG. luiz_tizo@hotmail.com

2. Mestre em Zootecnia, Professor das Faculdades Associadas de Uberaba FAZU, Uberaba, MG

3. Mestre em Saúde Animal - UnB - Professor de Patologia da Universidade de Uberaba - UNIUBE - Uberaba, MG

Recebido em: 08/09/2015 - Aprovado em: 14/11/2015 - Publicado em: 01/12/2015 DOI: http://dx.doi.org/10.18677/Enciclopedia_Biosfera_2015_216

\begin{abstract}
RESUMO
O experimento foi realizado com o objetivo de avaliar se o sistema de criação confinado ou livre interferem na qualidade total dos ovos obtidos por poedeiras no segundo ciclo de postura. Utilizou-se 50 poedeiras em sistema livre e 50 em sistema confinado, oriundas de uma mesma granja todas com 84 semanas. Foram coletados 33 ovos de cada tratamento, dos quais 30 foram analisados para as características de peso do ovo, altura e porcentagem de albúmen, unidade Haugh, índice de gema, espessura, peso e porcentagem de casca, deste total de ovos 10 foram analisados para averiguação de propriedades físico-químicas; foi realizado teste de Salmonella sp. nos três restantes de cada tratamento. Foi feita análise estatística para as características citadas pelo software Sisvar $\AA^{\circledR}$. Houve diferença para altura de albúmen, unidade Haugh, índice de gema, peso e porcentagem de casca, e porcentagem de albúmen, as demais características não foram observado diferença. Os resultados negativos para contaminação por Salmonella sp. sugerem que o risco de transmissão de salmonelose em ambos os sistemas é o mesmo.
\end{abstract}

PALAVRAS-CHAVE: avicultura alternativa; índice de gema; qualidade de ovo; Salmonella; unidade Haugh

\section{EXTERNAL AND INTERNAL QUALITY OF EGGS OBTAINED ON TWO SYSTEMS OF LAYERS OF CREATION}

\begin{abstract}
The experiment was conducted in order to assess whether the housing system confined or free interfere with overall quality of eggs from laying hens in the second laying cycle. 50 layers were used in free system and 50 in the confined system, derived from the same farm. Thirty three eggs were collected and analized from each treatment, 30 for egg weight, albumen height and percentage, Haugh unit, yolk index, thickness, weight and shell percentage. Ten of the 30 eggs were analyzed for investigation of physicochemical properties; Salmonella test was performed in the remaining three of each treatment. Statistical analysis was performed for the cited characteristics by Sisvar ${ }^{\circledR}$ software. There were differences in albumen height, Haugh unit, yolk index, weight and shell percentage, and percentage of albumen.
\end{abstract}


The remaining characteristics did not apresent statistical difference. The free system ensures greater welfare which influences on some properties. No statistical difference was found for the physico-chemical characteristics. The negative result for contamination by Salmonella sp. suggest that the risk of salmonela transmission in both systems is the same.

KEY WORDS: alternative poultry; yolk index, egg quality, Salmonella, Haugh unit

\section{INTRODUÇÃO}

A avicultura de postura está à frente de outras atividades da pecuária nacional no que se refere à estabilidade de mercado e às vantagens oferecidas ao consumidor. Isto pode ser verificado pela caracterização da cadeia avícola do ovo, que pode ser encarado como um alimento natural, equilibrado e de baixo preço, rico em todos os elementos necessários para a formação de um ser vivo completo. Atualmente, tem-se observado alterações nos indicativos de baixo consumo nacional devido ao grau de articulação do setor, sobretudo direcionado para a quebra dos paradigmas associados ao consumo de ovos (MAGALHÃES, 2007). Segundo informações da União Brasileira de Avicultura (UBABEF, 2012), o consumo per capita de ovos no Brasil ficou em 161,53 unidades no ano de 2012 e de acordo com dados obtidos pela ABPA (2015), o Brasil chega ao consumo per capita de 182 unidades por ano, em 2014, ultrapassando as 168 unidades registradas em 2013. Um desses paradigmas se deriva da cultura popular de que ovos de aves totalmente confinadas não tem as mesmas propriedades que os ovos de aves semi-confinadas ou livres, os denominados "ovos tipo caipira", além do colesterol que causa muito espanto nos consumidores. Sabe-se que o seu teor presente no ovo não causa danos à saúde e que não há correlação direta entre consumo de ovo e doenças cardiovasculares (PIZZOLANTE, 2012).

Os ovos são uma importante fonte protéica (com cerca de 13\% de proteínas), sendo considerados alimentos ricos em proteína e com baixo teor de gordura $(8,9 \%)$, tendo na porção lipídica, maiores concentrações de ácidos graxos instaurados. Desempenham diversas propriedades funcionais que proporcionam aos alimentos cor, viscosidade, emulsificação, geleificação e formação de espuma. Um ovo tem em média 60 gramas, nas quais encontra-se apenas $1,5 \mathrm{~g}$ de gordura saturada. As propriedades do ovo variam conforme a alimentação da ave, além do mais, suas proteínas não perdem suas propriedades ao cozimento, elas apenas coagulam (SARCINELLI et al, 2007). GESSULLI (1999) ressalta que os ovos, assim como o leite, são de fácil digestão, sendo que $98 \%$ das proteínas são absorvidas e são aproximadamente iguais às proporções de utilização das gorduras.

A produção nacional de ovos de galinha foi de 250 milhões de dúzia, com um plantel de 135 milhões de aves no $1^{\circ}$ trimestre de 2015, segundo os dados das Pesquisas Trimestrais do Abate de Animais, do Leite, do Couro e da Produção de Ovos de Galinha, divulgados pelo Instituto Brasileiro de Geografia e Estatística (IBGE, 2015).

Pôde-se verificar que as exportações de ovos somaram 26,8 mil toneladas em 2012, com crescimento de $61,2 \%$ em relação a 2011. A receita cambial, de US $\$ 42,6$ milhões, teve incremento $50,8 \%$. Angola, com $47 \%$ do total, e Emirados Árabes Unidos, com $38 \%$ das importações, foram os principais compradores (UBABEF, 2012).

Uma nova vertente da avicultura foi consolidada com a introdução de um novo conceito de sistema de produção denominada avicultura "caipira". A ave caipira é aquela proveniente de uma criação, cuja alimentação deve ser suprida basicamente 
por alimentos naturais como pasto, capim picado, insetos, minhocas, etc. Este conceito permanece inalterado; o que mudou foi a qualidade da ave que está sendo criada neste sistema: uma ave melhorada geneticamente, que adquiriu precocidade e potencial de crescimento sem perder as características de rusticidade. Deste novo contexto, surgiu o conceito de Avicultura Alternativa, como sendo um sistema ecologicamente correto e socialmente justo de produção de "carne e ovos caipira" (COSTA et al, 2005).

De acordo com GESSULLI (1999) há um crescente interesse das pessoas por produtos naturais promoveu um aumento da procura por frangos e ovos caipira nas cidades, elevando o preço e, consequentemente, despertando o interesse de muitos produtores rurais por esta atividade. Segundo ABREU et al. (1997) os produtores, além do interesse pelas fêmeas na produção de ovos, ainda reservam os machos para o crescimento e engorda o que gera lucro com as vendas futuras para o abate pois a carne é muito apreciada pela coloração e seu sabor diferenciado. Isso geralmente ocorre em plantéis de propriedades onde trabalha-se o aproveitamento dos animais tanto para corte quanto para produção de ovos, pois se for para escolher somente uma atividade deve-se adotar uma genética específica de aves.

De acordo com SILVA (2010) a produção de ovos deve ser quase que obrigatoriamente de casca vermelha, pois os ovos brancos provêm exclusivamente de granjas industriais e não seriam aceitos pelo consumidor como sendo do tipo caipira. O mesmo autor ressalta que a pastagem para aves no sistema caipira é a principal diferença entre o sistema convencional, levando em consideração esta afirmação, GESSULLI (1999) explica que as xantofilas (pigmentos vegetais) contidas nas verduras ou pastagens deixam a pele da ave e a gema do ovo com uma pigmentação intensa que é uma característica fundamental na diferenciação do produto para a comercialização.

Para a avaliação da qualidade do ovo é analisado o aspecto externo, através do peso e da casca. O peso não é indicador de qualidade nutricional do ovo, mas serve para padronizar a comercialização. A casca é a embalagem natural dos ovos, naqueles considerados de primeira qualidade, independentemente da cor, a casca deve ser limpa, íntegra, sem trincas e, ainda, sem deformações. Cascas resistentes ajudam a proteger a parte interna de microrganismos e dependem de rações com níveis suficientes e equilibrados de nutrientes, como cálcio, fósforo e vitamina $D_{3}$. Grandes deformações na casca prejudicam o visual e ainda indicam problemas sanitários nas poedeiras, além de serem descartados pela indústria por não apresentarem padrões comerciais (OLIVEIRA, 2010).

Segundo HARDER e colaboradores (2008), pode-se avaliar a qualidade do ovo, verificando a altura de albúmen e gema, unidade Haugh, índice de gema e espessura de casca. Diante do fator cultural, sem o conhecimento científico sobre a composição e nutrientes dos ovos obtidos em sistemas diferentes de criação de aves e características que comprovem sua qualidade, o presente estudo objetivou comparar se os sistemas de criação em confinamento e criação livre interferem na qualidade total dos ovos obtidos por poedeiras no segundo ciclo de postura.

\section{MATERIAIS E MÉTODOS}

O experimento foi realizado em dois locais, sendo um no Setor de Suinocultura (integrado com aves no sistema livre, "caipira" para postura), situado na Fazenda Escola das Faculdades Associadas de Uberaba (FAZU-FUNDAGRI), na cidade de Uberaba-MG, cujas coordenadas geográficas são: longitude de 4757' 54", latitude de $19^{\circ} 43^{\prime} 88^{\prime \prime}$, temperatura média anual de $23,0^{\circ} \mathrm{C}$ e precipitação pluviométrica de 
1750 mm e; outro em um galpão avícola de postura, situado na Granja São João em Delta-MG, cujas coordenadas geográficas são: longitude de $47^{\circ} 48^{\prime} 42 "$, latitude de $19^{\circ} 56^{\prime} 12^{\prime \prime}$, temperatura média anual de $23,4^{\circ} \mathrm{C}$ e pr ecipitação pluviométrica anual de $1114,4 \mathrm{~mm}$. O experimento teve início em abril de 2013 e término em meados de maio do mesmo ano.

Foram utilizadas 100 aves comerciais da linhagem Hy-line Brown, de aproximadamente 85 semanas, em segundo ciclo de produção, oriundas de uma granja comercial situada na região de Delta-MG. As aves foram divididas em dois sistemas nos quais 50 aves permaneceram em sistema livre, e 50 permaneceram em sistema confinado com ambiente e alimentação controlados, dispostas em gaiolas com densidade média de seis aves.

As aves do sistema livre ficaram em piquetes de pastagem de Sistema Intensivo de Suínos Criados ao Ar Livre (SISCAL) situado na FAZU. Receberam água à vontade em bebedouro pendular e ração comercial em comedouros tubulares na quantidade de 120 gramas/ave/dia. Havia uma cobertura de feno no local de alimentação, onde os ovos eram postos além dos ninhos de madeira adicionados no mesmo local. As aves tinham a possibilidade de aproveitar resíduos de ração nas excretas dos suínos que estiveram no local, simulando o hábito de alimentação aleatório das aves criadas como caipira nas propriedades como fazendas.

As aves confinadas permaneceram na granja Ovos São João, em gaiolas, com umidade e ventilação controladas, água à vontade em bebedouros de pressão e ração comercial fornecida em comedouro tipo calha, na quantidade de 120 gramas/ave/dia.

Os ovos foram recolhidos diariamente em cada tratamento, porém a avaliação da qualidade dos ovos somente foi mensurada após um período de adaptação e aclimatação das aves de três semanas. Foram coletados 33 ovos por sistema de criação. A coleta foi feita com luva e cada ovo foi enumerado e guardado em caixas limpas de papel, com divisórias para que não ocorresse o contato uns com os outros, a partir deste instante foram armazenados em ambiente seco e isento de radiação por luz. No mesmo dia, foram analisados 30 ovos dos dois tratamentos para as seguintes características: pesagem, altura e porcentagem de albúmen, unidade Haugh, índice de gema, espessura, peso e porcentagem de casca.

Cada ovo foi submetido à pesagem em balança de precisão, conforme descrito por MAGALHÃES (2007). Após a pesagem, os ovos foram quebrados e seu conteúdo (albúmen+gema) colocado em superfície de vidro plana e nivelada. Foi mensurada a altura do albúmen $(\mathrm{mm})$, por meio da leitura do valor indicado por um paquímetro digital adaptado a um tripé. De posse dos valores de peso do ovo (g) e altura do albúmen (mm), foi utilizada então a fórmula descrita por PARDI (1977), para o cálculo da unidade Haugh:

$$
\begin{aligned}
& U H=100 \log \left(H+7,6-1,7 \mathrm{~W}^{0,37}\right) \\
& \text { Onde, } \mathrm{H}=\text { altura do albúmen }(\mathrm{mm}) \text { e } \mathrm{W}=\text { peso do ovo }(\mathrm{g}) \text {. }
\end{aligned}
$$

Foram mensuradas a altura e diâmetro da gema com um paquímetro digital adaptado a um tripé. $O$ índice de gema foi obtido através da metodologia descrita por MAGALHÃES (2007).

$$
\mathrm{IG}=\frac{\mathrm{AG}(\mathrm{mm})}{\mathrm{DG}(\mathrm{mm})}
$$


Onde, $A G$ = altura de gema e $D G$ = diâmetro de gema, segundo a metodologia descrita por MAGALHÃES (2007).

As cascas tiveram o restante de albúmen lavado por água corrente e foram postas para secar durante quatro horas em uma estufa a $56^{\circ} \mathrm{C}$, as membranas internas foram ignoradas e foi feita a medida da espessura da casca com um paquímetro em três pontos na região equatorial, adotando a média para análise estatística.

Para espessura e porcentagem de casca foi adotado a metodologia adaptada de MAGALHÃES (2007).

$$
\% \mathrm{C}=\frac{\mathrm{PC}(\mathrm{g})}{\mathrm{PO}(\mathrm{g})} \times 100
$$

Onde, $\mathrm{PC}=$ peso da casca e $\mathrm{PO}=$ peso do ovo.

Para calcular a porcentagem de albúmen $(\% A)$, foi adotada a seguinte metodologia:

$$
\% A=\frac{P A(g)}{P O(g)} \times 100
$$

Onde, $\mathrm{PO}=$ peso do ovo e PA = peso do albúmen.

Os dados foram compilados em um delineamento inteiramente casualizado para cada característica, com dois tratamentos e 30 repetições, sendo cada ovo uma repetição, e foram submetidos a análise de variância e as médias comparadas pelo teste de Tukey $(p<0,05)$ no software Sisvar®.

Dez, dos 30 ovos analisados de cada tratamento, foram escolhidos aleatoriamente para a análise de matéria seca, teor de proteína, extrato de lipídios (extrato etéreo), matéria mineral e carboidratos. Os três ovos excedentes foram testados para infecção por Salmonella sp. conforme metodologia do Instituto Adolfo Lutz - SP (2008), aplicada pelo laboratório de análise de alimentos e microbiologia da FAZU.

\section{RESULTADOS E DISCUSSÃO}

Foi observada diferença estatisticamente significativa para os aspectos de qualidade testados $(p<0,05)$, exceto para peso e espessura de casca. Os resultados obtidos nos tratamentos estão agrupados na Tabela 1.

Em relação ao peso do ovo, não houve diferença significativa nos dois

tratamentos, tal fato pode ser explicado pela ausência de diferença etária ou de linhagem das aves, uma vez que todas possuíam a mesma procedência. A princípio o manual da linhagem Hy-line Brown deixa estabelecido um peso médio de aproximadamente 65,1 g/ovo para poedeiras com 84 semanas de vida. Logo, a média de peso obtida no experimento está dentro do estipulado pelo manual Hy-line Brown (2012). Devido ao peso dos ovos obtidos no sistema livre estes são classificados como "jumbo" que são aqueles com peso padrão de no mínimo 66 gramas (LEMOS et al., 2015). 
Tabela 1. Qualidade dos ovos obtidos em sistema livre e confinado.

\begin{tabular}{lcccccccc}
\hline Tratamento & $\begin{array}{c}\text { Peso do } \\
\text { ovo }(\mathrm{g})\end{array}$ & $\begin{array}{c}\text { Altura de } \\
\text { albúmen } \\
(\mathrm{mm})\end{array}$ & $\begin{array}{c}\text { Unidade } \\
\text { Haugh }\end{array}$ & $\begin{array}{c}\text { Indice } \\
\text { de } \\
\text { gema }\end{array}$ & $\begin{array}{c}\text { Peso de } \\
\text { casca } \\
(\mathrm{g})\end{array}$ & $\begin{array}{c}\text { Espessura } \\
\text { de casca } \\
(\mathrm{mm})\end{array}$ & $\begin{array}{c}\text { casca } \\
(\%)\end{array}$ & $\begin{array}{c}\text { albúmen } \\
(\%)\end{array}$ \\
\hline Sistema Livre & $66,90 \mathrm{a}$ & $6,70 \mathrm{a}$ & $78,18 \mathrm{a}$ & $0,46 \mathrm{a}$ & $5,65 \mathrm{~b}$ & $0,302 \mathrm{a}$ & $8,47 \mathrm{~b}$ & $66,91 \mathrm{a}$ \\
Sistema Confinado & $65,78 \mathrm{a}$ & $5,69 \mathrm{~b}$ & $70,93 \mathrm{~b}$ & $0,42 \mathrm{~b}$ & $6,26 \mathrm{a}$ & $0,315 \mathrm{a}$ & $9,54 \mathrm{a}$ & $63,93 \mathrm{~b}$ \\
CV $(\%)$ & 7,35 & 21,58 & 13,98 & 8,00 & 12,62 & 12,43 & 12,49 & 4,29 \\
\hline
\end{tabular}

Médias seguidas de letras iguais na mesma coluna não diferem estatisticamente (Tukey $5 \%$ ).

A qualidade do ovo é medida frequentemente levando em consideração principalmente 0 albúmen. As aves do sistema caipira apresentaram maiores quantidades de albúmen (SCATOLINI-SILVA et al., 2013). A respeito da porcentagem de albúmen, o maior resultado obtido no experimento pode ter sido influenciado pela menor porcentagem de casca. Assim, a interferência da casca sobre o peso do ovo é menor em relação ao sistema confinado. MAZZUCO (2008), afirma que o ovo tem aproximadamente $63 \%$ de albúmen, assim, quanto menor for a quantidade de casca e gema presente no ovo total, maior será essa quantidade de albúmen.

Ovos do sistema livre apresentam maior altura de albúmen e, consequentemente, maior unidade Haugh; portanto, melhor qualidade (JONES \& MUSGROVE, 2005). Ovos considerados de qualidade excelente (AA) devem apresentar valores de UH superiores a 72; ovos de qualidade alta (A), entre 60 e $72 \mathrm{UH}$, e ovos de qualidade inferior (B), com valores de UH inferiores a 60 (XAVIER, 2008). Os ovos do sistema livre demonstraram uma qualidade excelente (AA) em relação ao do sistema confinado $(A)$.

BARBOSA FILHO (2004), ao avaliar o efeito de criação em cama ou gaiola, verificou que a condição estressante das gaiolas era responsável pelo declínio da UH do ovo, assim como, o índice de gema justamente o que aconteceu no presente estudo, pois as aves em sistema livre provavelmente tinham descargas hormonais de estresse (cortisol) inferior às que estavam confinadas e com seu espaço restrito nas gaiolas.

Levando em consideração a normalidade de índice de gema que varia de 0,3 a 0,5 (SCATOLINI-SILVA et al., 2013), os resultados estão de acordo com os de Barbosa Filho (2004) que encontrou valores de 0,44 a 0,41, para a linhagem Hy-Line Brown. O peso da casca está interligado à sua porcentagem total do ovo, sendo as duas com índices a favor do tratamento confinado. Segundo BARBOSA FILHO (2004), a queda nos valores de porcentagem de casca pode ser explicada pela maior carga de estresse a que as aves criadas no sistema de gaiolas são submetidas, além do fato de que, neste sistema o estresse térmico é mais acentuado, devido às condições de confinamento das aves que dificultam as perdas de calor (CASTILHO et al., 2015).

MAZZUCO (2008) explica a fisiologia da formação da casca, que ocorre no útero, quando o cálcio circulante na corrente sanguínea é depositado após ser secretado pelas glândulas calcíferas do oviduto, formando uma estrutura cristalina característica. A deposição do cálcio é auxiliada por atividade enzimática, especialmente da anidrase carbônica que catalisa a reação $\left(\mathrm{CO}_{2}+\mathrm{H}_{2} \mathrm{O} \leftrightarrow \mathrm{H}_{2} \mathrm{CO}_{3}\right)$, com finalização após a vigésima hora no útero. Como a deposição de carbonato de 
cálcio é um processo lento e delicado, qualquer tipo de estresse pode fazer com que o ovo seja expelido antes do tempo normal, fazendo com que apareça casca mais fina ou casca mole.

No terço final do experimento, as aves criadas no sistema livre sofreram ataques de predadores naturais (raposas), assim as aves passaram por alto estresse durante a noite, o que interferiu na qualidade da casca durante a postura (CASTILHO et al., 2015). Outra hipótese para o declínio da qualidade de casca no sistema livre se deve à alimentação, pois as aves tinham vegetais e insetos para se alimentarem além da ração, assim não conseguiam uma quantidade de cálcio adequada para deposição no ovo. Além do mais, poedeiras em segundo ciclo de postura tem dificuldade de mobilizar cálcio dos ossos e fixar no ovo devido à distúrbios relacionados com a idade. No entanto, a espessura não diferiu quanto aos tratamentos, o que discorda com os trabalhos de SILVA (2004) e MAGALHÃES (2007).

SOUZA (2012) ao realizar uma pesquisa sobre qualidade de ovos marrons de granja e caipira verificou que os ovos de granja apresentaram maior \% de albúmen, menor \% de casca, melhor índice de gema e unidade Haugh, o que entra em contradição com os resultados encontrados.

As análises físico-químicas dos ovos de ambos os sistemas testados não apresentaram diferenças estatisticamente significativas $(p>0,05)$, mostrando que os tratamentos não diferiram quanto aos teores de nutrientes avaliados. Os dados obtidos nas análises estão agrupados na Tabela 2.

Tabela 2. Composição fisico-química dos ovos.

\begin{tabular}{|c|c|c|c|c|c|}
\hline Tratamento & $\begin{array}{c}\text { Carboidratos } \\
(\%)\end{array}$ & $\begin{array}{c}\text { Extrato } \\
\text { Etéreo }(\%)\end{array}$ & $\begin{array}{c}\text { Matéria } \\
\text { Seca }(\%)\end{array}$ & $\begin{array}{l}\text { Proténa } \\
(\%)\end{array}$ & $\begin{array}{c}\text { Matéria } \\
\text { Mineral (\%) }\end{array}$ \\
\hline Sistema Livre & $0,69 \mathrm{a}$ & $9,69 \mathrm{a}$ & $29,82 \mathrm{a}$ & $11,37 \mathrm{a}$ & $0,93 \mathrm{a}$ \\
\hline Sistema Confinado & $0,71 \mathrm{a}$ & $8,82 \mathrm{a}$ & 28,34 a & $10,68 \mathrm{a}$ & $1,02 \mathrm{a}$ \\
\hline
\end{tabular}

O ovo constitui-se basicamente de $74 \%$ de água, $12,5 \%$ de proteínas, $12 \%$ de lipídeos, $1 \%$ de sais minerais e $0,5 \%$ de carboidratos (FONSECA, 1985). A porcentagem de carboidratos nos ovos varia de $0,5 \%$ a $1,6 \%$ (SARCINELLI et al., 2007; UNICAMP, 2011). No presente estudo, os valores de carboidratos em ambos os sistemas de tratamento estão dentro dos valores normais.

As análises relativas a contaminação por Salmonella sp foram negativas em ambos os sistemas testados. ONO (2011) ao realizar um estudo em 35 amostras de ovos comerciais destinados a consumo humano, não encontrou nenhum tipo de Salmonella sp. Ovos com qualidade ruim de casca são susceptíveis a contaminações microbiológicas, pois a porosidade é maior e suas deformações facilitam a entrada destes patógenos (PASCOAL et al., 2008; CASTILHO et al., 2015). Embora, os ovos analisados tivessem baixa qualidade de casca, os resultados negativos, mesmo no sistema livre no qual os ovos eram postos em sua maioria nas camas e em contato direto com fezes, sugere novos estudos afim de confirmar tal susceptibilidade. 


\section{CONCLUSÃO}

Em termos nutricionais os ovos obtidos dos dois sistemas não diferiram estatisticamente. A ausência de contaminação por Salmonella sp. sugere que os ovos do sistema livre apresentam risco de transmissão de salmonelose semelhante ao sistema comercial. Novos estudos serão conduzidos a fim de confirmar esta hipótese.

\section{REFERÊNCIAS}

ABREU, R. D.; VIEIRA JUNIOR, J. R.; COSTA, M. Produção de Frangos e Ovos Caipiras. Brasília: Senar, v. 1,1997, 116p.

A Hora do Ovo. Sobem consumo e produção de ovos no Brasil; caem exportações. Disponível em: < http://www.ahoradoovo.com.br/no-mundo-do-ovo/noticias/?id=761| sobem-consumo-e-producao-de-ovos-no-brasil-caem-exportacoes>. Acesso em 19 de out. 2015.

Associação Brasileira de Proteína Animal - ABPA. Disponível em: < http://abpa$\mathrm{br}$.com.br/setores/avicultura/mercado-interno/ovos/consumo-per-capita>. Acesso em 19 de out. 2015.

BARBOSA FILHO, J. A. D. Avaliação do bem-estar de aves poedeiras em diferentes sistemas de produção e condições ambientais, utilizando análise de imagem. 2004. Dissertação (Mestrado em Agronomia) Escola Superior de Agricultura Luiz de Queiroz, Piracicaba, 2004. 123 f.

CASTILHO, V. A. R.; GARCIA, R. G.; LIMA, N. D. S.; NUNES, K. C.; CALDARA, F. R.; NÄÄS, I. A.; BARRETO, B.; JACOB, F. G. Bem-estar de galinhas de poedeiras em diferentes densidades de alojamento. Brazilian Journal of Biosystems Engineering, v. 9, p. 122-131, 2015.

COSTA, M. V.; CASTRO JÚNIOR, W. L.; BOTELHO FILHO, F. B. Custo de produção na avicultura alternativa do Distrito Federal. Anais... XLIII Congresso da SOBER, Sociedade Brasileira de Economia e Sociologia Rural. Ribeirão Preto. Julho 2005.

FONSECA, W. Carne de ave e ovos: Vademecum. 2a ed. São Paulo: Icone, p. 190, 1985.

GESSULLI, O. P. Avicultura Alternativa. OPG Editores LTDA. Porto Feliz, SP. 1999, 218p.

HARDER, M. N. C.; BRAZACA, S. G. C.; SAVINO, V. J. M.; COELHO, A. A. D. Efeito de Bixa orellana na alteração de características de ovos de galinhas. Ciência Agrotécnica, Lavras, v. 32, n. 4, p. 1232-1237, 2008.

Hy-line Brown. Manual de poedeira comercial. Hy-Line do Brasil, Edição 2. Nova Granada-SP, 2012. Disponível em: <http://www.hyline.com/UserDocs/products /BRN_COM_POR.pdf>. Acesso em: 20 de out. 2015. 
INSTITUTO NACIONAL DE METEOROLOGIA - INMET. Dados Meteorológicos (2013). Disponível em: < http://www.inmet.gov.br>. Acesso em: 20 de out. 2015.

INSTITUTO BRASILEIRO DE GEOGRAFIA E ESTATÍSTICA - IBGE. Pesquisas Trimestrais do Abate de Animais, do Leite, do Couro e da Produção de Ovos de Galinha. Disponível em:<http://www.sidra.ibge.gov.br/bda/default.asp?t=4\&z=t\& $0=1 \& u 1=1 \& u 2=1 \& u 3=1 \& u 4=1 \& u 5=1 \& u 6=1 \& u 7=1 \& u 8=1 \& u 9=1 \& u 10=1 \& u 11=1 \& u 12$ $=3 \& u 13=1 \& u 14=26674 \& u 15=1 \& u 16=1 \& u 17=1>$. Acesso em: 15 de ago. 2015.

Instituto Adolfo Lutz. Normas Analíticas do Instituto Adolfo Lutz: 1a Edição. Métodos Químicos e Físicos para Análises de Alimentos. São Paulo, SP. vol.1, cap. 17, p. 631-635, 1985.

JONES, D. R.; MUSGROVE, M. T. Effects of extended storage on egg quality factors. Poultry Science, v. 84, p. 1774-1777, 2005.

LEMOS, M. J.; CALIXTO, L. F. L.; TOGASHI, C. K.; OLIVEIRA, S. M.; PINHO, T. P.; MELO, A. L. P.; BARBOSA, M. I. M. J. Qualidade de ovos orgânicos produzidos no município de Seropédica - RJ. Revista Agropecuária Técnica, v. 36, n. 1, p. 50-57, 2015.

MAGALHÃES, A. P. C. Qualidade de Ovos Comerciais de Acordo com a Integridade da Casca, Tipo de Embalagem e Tempo de Armazenamento. Dissertação (Mestrado em Zootecnia). Instituto de Zootecnia, Universidade Federal Rural do Rio de Janeiro, Seropédica, RJ, 2007. 43p.

MAZZUCO, H. Ovo: alimento funcional, perfeito à saúde. Avicultura Industrial, v. 99, n. 1164, p. 12-16, 2008.

OLIVEIRA, D. D.; BAIÃO, N.C.; CANÇADO, S.V.; FIGUEIREDO, T.C.; LARA, L. J. C. LANA, A. M. Q. Fontes de lipídios na dieta de poedeiras: desempenho produtivo e qualidade dos ovos. Arquivo Brasileiro de Medicina Veterinária e Zootecnia, v. 62, n. 3, p. 718-724, 2010.

ONO, M. A. Pesquisa de Salmonella sp. na casca e no conteúdo de ovos destinados ao consumo humano. Biológico, São Paulo, v. 73, n. 2, p. 204-206, 2011.

PARDI, H. S. Influência da comercialização na qualidade dos ovos para o consumo. Rio de Janeiro, 1977. Dissertação (Mestrado) - Universidade Federal Fluminense, 73p.

PASCOAL, L. A. F.; BENTO JUNIOR, F. A.; SANTOS, W. S.; SILVA, R. S.; DOURADO, L. R. B.; BEZERRA, A. P. A. Qualidade de ovos comercializados em diferentes estabelecimentos na cidade de Imperatriz-MA. Revista Brasileira de Saúde e Produção Animal, v. 9, n. 1, p. 150-157, 2008.

PIZZOLANTE, C. C. O ovo e o mito do colesterol. Pesquisa \& Tecnologia, v. 9, n. $1,2012$. 
SARCINELLI, M.F.; VENTURINI, K.S.; SILVA L.C. Caracteristicas dos ovos. Boletim Técnico, Universidade Federal do Espirito Santo, 2007. Disponível em: $<$ http://www.agais.com/telomc/b00707_caracteristicas_ovos.pdf>. Acesso em: 20 de out. 2015.

SCATOLINI-SILVA, A. M.; BORBA, H.; GIANPIETRO-GANECO, A.; SOUZA, P. A.; BOIAGO, M. M.; MELLO, J. L. M.; VAZ, A. B. S. Qualidade física de ovos armazenados em diferentes condições de embalagens sob temperatura ambiente. Arch. Zootec., v. 62, n. 238, 2013.

SILVA, F. H. A. Curso teórico-prático sobre técnicas básicas de avaliação de qualidade do ovo. Piracicaba: ESALQ. s.ed. 2004.

SILVA, R. D. M. Sistema Caipira de Criação de galinhas. 2 ed. Editora Aprenda Fácil. Viçosa/MG, p. 203, 2010.

SOUZA, D. O.; PERIM, F. S.; MINAFRA, C.; MARTINEZ, K. L. A.; MANI, I. P. Qualidade interna e externa de ovos de granja marrom e caipira de acordo com a condição e o tempo de armazenamento In: I Congresso de Pesquisa e PósGraduação do Câmpus Rio Verde do IFGoiano. 2012, Rio Verde-GO. Anais... Rio Verde-GO: IFGoiano, 2012. p. 1-4.

União Brasileira de Avicultura - UBABEF. Relatório anual (2012). Disponível em: $<$ http://www.brazilianchicken.com.br/files/publicacoes/d220421fe22b294a31a584138 b5fda95.pdf>. Acesso em: 15 de ago. 2015.

Universidade de Campinas - UNICAMP. Tabela Brasileira de Composição de Alimentos - TACO. 4aㅡ edição revisada e ampliada. Campinas - SP, 2011.

XAVIER, I.M.C.; CANÇADO, S.V.; FIGUEIREDO, T. C.; LANA, L. J. C.; SOUZA, M. R.; BAIÃO, N. C. Qualidade de ovos de consumo submetidos a diferentes condições de armazenamento. Arquivo Brasileiro de Medicina Veterinária e Zootecnia, UFMG, v. 60, n. 4, p. 953-959, 2008. 